\title{
Landscapes of History in the Novels of Lawrence Norfolk
}

\section{Ladislav Nagy}

This article deals with novels by Lawrence Norfolk which are read with a focus on their visual quality and the way they depict history. It is argued that Norfolk's historical novels are unique in their portrayal of "landscapes of history", large canvases in which individual characters play marginal, or a rather insignificant role. This approach distinguishes Norfolk from much of contemporary historical fiction, albeit at times this strategy might not be wholly satisfactory from a critical perspective. However, the article claims that Norfolk's novels are intellectually inspiring since, similar to landscape, they invite a certain gaze, yet deny us the possibility of naming, of conceptualising. They provide readers with impressive vistas on history, which is seen as something too large to understand and penetrate. In this the novels are anti-humanistic. Individual characters (and their actions) are insignificant, or significant only to such an extent that they subscribe to some mythical framework, as Norfolk showe in, arguably, his best novel, In the Shape of a Boar (2000).

\section{Keywords}

Contemporary British fiction; historical novel; anti-humanism; myth in fiction; postmodern narrative

Lawrence Norfolk, one of the most ambitious historical novelists today, is, above all, a painter of vast historical panoramas. The emphasis on the visual aspect is evident in his work. Striking the reader in the author's very first novel, Lemprière's Dictionary (1991), it is gradually being strengthened - to visions of the creation of the European continent in The Pope's Rhinoceros (1996), variations on the Homeric legend in the novel In the Shape of a Boar (2000) or to splendid views of Baroque cuisine in Fohn Saturnall's Feast (2013).

This makes Norfolk rather different from other major historical novelists of recent decades who have turned their attention to the past where they found striking stories to be used in the narrative. It is indeed remarkable that the term "romance" is used so very often. Suzanne Keen speaks about the "romances of the archive" when discussing books by Peter Ackroyd, Penelope Lively, Barry 
Unsworth and A. S. Byatt; Mariadele Boccardi speaks about "romances of the past" (A. S. Byatt, Lindsay Clarke, Graham Swift) or "romances of withdrawal (James Robertson, Philip Hensher, Ronan Bennett); Amy J. Elias speaks of "metahistorical romances" in relation to Peter Ackroyd.

Oddly enough, it was precisely the genre of the romance against which the historical novels defined themselves, claiming the status of the novel as a genre of higher authority. While romances were seen as something frivolous, the novel was considered more serious. Many historical novels written today comfortably accept the legacy of romance. Lawrence Norfolk, I want to argue in this article, opts for a different route. What he offers to his readers is indeed an attempt at a novel, but it is a novel of a very unique type - a novel where characters are of no great significance and where what is at stake is the desire to capture the vastness of historical time and to emphasise the insignificance of human players on large historical canvases.

The strong visual quality opens up several dimensions in Norfolk's work. First, it distances him clearly from genre fiction and prevents him from the temptation to write merely a pastiche of older novels, as is often the case with neo-Victorian fiction. Second, it allows him to remain in the vaguely delineated area between the explicit and the implicit - this is especially important in arguably his best novel In the Shape of a Boar. In it, the reader is fascinated by a new, and rather impressive, retelling of a Homeric myth and drawn in the game of interpretation. As a narrator, Norfolk himself is unobtrusive, providing the readers with a hint and then hiding in the background. Third, magnificent visual scenes - compared by some critics to the films of Peter Greenaway - only help to strengthen the ambitions of the work; and, as stated above, Lawrence Norfolk is a most ambitious writer. Naturally, strong visual inspiration is double-edged: on the one hand, it is impressive, utterly fascinating the reader, on the other hand it can deprive the novel of its substance. A case in point is, I am afraid, the author's most recent book.

Let us look at Norfolk's work from a historical perspective. The twentyeight-year-old author published his debut novel Lemprière's Dictionary in 1991 to wide critical acclaim. It needs to be stressed that he met the demand for historical fiction and provided the readers with a book that sounded some echoes of Umberto Eco's historical novels (namely of the paranoid Foucault's Pendulum) but, besides that, it was appreciated for the brilliance of its language and vivid pictures of the past. Critics welcomed the novel with enthusiasm and even after some time it is still considered a masterly debut. Malcolm Bradbury, among others, regarded the novel highly, compared it to Eco's 
work and praised it as "widely read" (406), a quality shared by all the other books by the author (i.e., that the novels are based on thorough research). It should be emphasised though that this, too, is double-edged. The volume of research can impress the reader (Lemprière's Dictionary), it can even serve as a clue for interpretation of the novel (in the novel In the Shape of a Boar the first thirty pages are heavily annotated, which establishes a counterpoint to the author's imaginative gesture in the main body of the text), but in some cases it can be detrimental to the novel (which is precisely what happens in John Saturnall's Feast).

In the context of Norfolk's work as a whole, Lemprière's Dictionary is both characteristic and unique. It shares the elements outlined above, i.e., an emphasis on rich visuals and thorough research into historical detail; however, it stands out with its strong plot, which is something we do not find in Norfolk's later novels: The Pope's Rhinoceros has only a general narrative framework, which, moreover, serves as a vehicle for individual episodic pictures; in In the Shape of a Boar the first part of the book retells a myth, the second vaguely outlines an individual life-story which needs to be complemented by the reader from extra-textual sources; in fohn Saturnall's Feast the story is rather unimportant and its only aim is to lead the reader to an opulent feast where the author fully displays his vast knowledge of English Baroque cuisine.

From the genre perspective, Lemprière's Dictionary is a novel sometimes labelled "novels of conspiracy". The book was published precisely at the time when this type of literature had become increasingly popular among readers, with the vogue culminating some time later in Dan Brown's bestsellers. Conspiracy theories and conspiracy novels are nothing new; they have been with us throughout history although - as Theodore Ziolkowski observes in his recent book Lure of the Arcane - "Whereas recent generations have tended to find their conspiracies in politics and government, the past often sought its mysteries in religious cults or associations" (9). Brown erases this distinction and presents, as the great conspirator, the Vatican, i.e., an institution combining spiritual and political agendas. Ziolkowski comments on the attractiveness of conspiracy theories and their reflection in novels:

In our eagerness to blame others for our problems, we feel an impulse to identify a specific enemy. Naming a conspiracy is simpler than undertaking the more complicated analysis of the motives and means of the institutions - financial, political, ideological, religious, military, and others - that constitute our society and easier than accepting the fact that 
a single deranged individual is responsible for an assassination or some other terrible act. (7)

In a wider framework, in which conspiracy is used by Brown, but also by Norfolk, a conspiracy theory provides an escape vis-à-vis the possibility that the world has no meaning. If the recent historical novels ask about the meaning of history, then it is perhaps more acceptable and comfortable to stick to an idea that history and our lives are manipulated by some force, however malevolent, that shapes history according to its interests and heads towards some pre-set target, rather than to face the dreadful possibility that what happens around us has no meaning at all and that what lies ahead of us is only nothingness. While Dan Brown satisfies the demand for such a conspiracy theory in a rather direct or uncomplicated manner, Norfolk is much more sophisticated and plays with the reader's expectations.

The key to the story of Lempriere's Dictionary is in a conspiracy to control world trade. The main protagonist is not a superhero, and he finds himself in the story rather by accident; it is also by accident that he finds the solution to the mystery, a solution simultaneously bizarre and comic, which shifts Norfolk's novel onto a level quite different from that of Brown's works. Norfolk masterfully uses the conspiracy theory which is applied in the novel on the character of the lexicographer John Lemprière, the author of the first EnglishLatin dictionary, and to history as such. The plot elements of the novel are as follows: the siege of La Rochelle and the fight between the Catholic majority and Huguenot minority, the mass murder of the latter and the escape of a few survivors to England; the establishment of the East India Company and the war over Asian trade; and, eventually, the work of John Lemprière, a classics scholar whose life story remains rather obscure, but this is not something that Norfolk finds deficient; on the contrary, the amount of information is quite sufficient for his purpose and equally important are the gaps, since it is into them that he can write his complex story of a large conspiracy.

The historical John Lemprière was born on Jersey and educated at Winchester and, later, at Oxford, where he obtained his doctorate in 1803 . He won fame by his Bibliotheca Classica or Classical Dictionary containing a full Account of all the Proper Names mentioned in Ancient Authors. This is not, strictly speaking, a dictionary but rather a compendium to Ancient mythology and history which pervade one another without a clear boundary.

It needs to be said though that at the time when the real Lemprière was compiling his book, the boundary was not clearly delineated in the discourse. 
The classics of early modern English literature such as those by Daniel Defoe, Jonathan Swift and Henry Fielding (his brother John features among the characters of the novel) call their fiction "histories", Defoe even goes as far as writing the semi-fictitious A fournal of the Plague Year; as if at a certain moment in history a text could belong to many genres at the same time: historiography for some, fiction for others. Or, in other words, as if it could fulfil different functions for different readers depending on the demands put on the text.

This two-dimensional character of the text, its location between history and fiction, may vaguely reflect a deeper clash in eighteenth-century culture, i.e., the dispute between the Ancients and the Moderns, so acutely described in Swift's The Battle of Books and The Tale of a Tub. The dispute, which originated in the French Academy between the lovers of classic authors discovered by the Renaissance, represented by Boileau, and the proponents of modern literature, represented by Perrault, swiftly crossed the Channel and occupied the English intelligentsia for most of the eighteenth century. In his response to Fontenelle's Of Ancient and Modern Learning, Sir William Temple made the famous metaphor that the modern man is just a dwarf standing on the "shoulders of giants". The metaphor captures the very essence of the dispute. While the Ancients believe that everything important has already been discovered and that - to put it simply - new experience is not possible, the Moderns opine the contrary, that new experience is necessary to remedy the errors of the past. The above mentioned satires by Swift are without a victor, but this is not important after all. What is more significant is that they provide a parody of the heroic epic and ridicule the idea that one particular period is exceptional and that derivative literary works are inferior.

Later, in the novel genre, the victory goes to the Moderns. The novel, as it developed in England from Defoe to Richardson to Fielding to the Victorians, banished classic models and embraced the reality of contemporary life. Classical models were sidelined into the realm of poetry, including Romantic poetry which, otherwise, defined itself against Classicism. It is John Keats who remarked that Lemprière's book was a huge inspiration to him. In the novel, there was no place for classical patterns - the modern novel strives for uniqueness, experience and expression.

Is our experience unique though? And is it possible to say something new, or do we just, in different versions, say more or less the same? These substantial and disturbing questions are put forward by Lemprière's Dictionary. Its hero is the very opposite of such protagonists as Robinson Crusoe or Moll Flanders. What he experiences is not unique at all, it is rather a kind of shadow play, a 
series of scenes from Ancient mythology. It all starts with the murder of his father, who is savaged by dogs in a scene that in fact re-enacts the myth of Diane and Acteon. The series of "re-enactments" then continues in London, for which the young John, acting on the will of his father, leaves in order to study. Each and every step of his is watched, even predicted or determined, by the members of the Kabbalah, a board of the eight surviving shareholders of the East India company, among whom was one of the Lemprières. The family, however, soon strayed and was stricken by a curse. The same curse appears to fall on John who is driven by two strong motives: a desire for a beautiful girl who he wants to liberate from a villain, and the desire to avenge his father's death. Classical mythology is used in the text as a skeleton for a historical thriller.

It ends like a thriller. John Lemprière is not a James Bond but with some good luck he succeeds in achieving his goal. It should be stressed that Norfolk's debut novel develops along the same lines as novels of his probable model, Umberto Eco. Readers are given a novel of conspiracy, endowed with much historical detail and a strong story, the end of which, however fantastic and improbable, does not obscure the underlying message.

The first one, evidently, is a critique of the modern world as a place fully governed by commerce. Lemprière's Dictionary is in fact a remarkable commentary on the history of English literature: whereas Defoe's protagonists, Robinson Crusoe, Moll Flanders or Roxana, are hailed as the first individualists and personifications of a quite new approach to life and the world, turning their lives into a project, the world into an object which should be used, exploited and monetised, John Lemprière - as portrayed by Norfolk - is their very opposite. If Robinson Crusoe is called homo economicus, then John Lemprière is a homo classicus. He is fully immersed in the world of classical mythology. Events just happen to him and if he perceives in his life a plan or pattern, then quite certainly it is not the one forced upon the world by him, but one clearly drawn by the ancient authors. He is not at all interested in the modern world and his eventual achievement is more or less an accident.

The second concerns the authenticity of human stories. Lawrence Norfolk does not seem to believe in it very much, preferring what I call "landscapes of history". In the same way that Lemprière denies in his life the primarily economic motivation of the modern novel's protagonists, the structure of his life seems to contradict modern ideas of individuality, uniqueness and singularity. There is nothing like individuality in history, suggests Norfolk. Everything has been described by the ancient authors and the stronger the 
status of myth the more frequent and substantial it is. This, however, has a profound impact on writing about history, or particularly a historical novel: it is sufficient to compile old stories and to provide the set stage. And it is the set stage which is given a prominent position throughout Norfolk's work.

In his second novel Norfolk moves away from classical mythology (he will return to it in his third book) and makes an effort to create his own mythology. It is at the very beginning of The Pope's Rhinoceros that we are treated to a scene in which the north of Europe is born:

In ages still to come, boulder waste and till will speak of the ice pack's tortuous inching over buried rock and sandstone; moraines and drumlins of advances and recessions that gouge out trenches and shunt forward ridges... This surface interruption: a pale disc of light germinating in the snow-flecked sky suggests a radical tilt to the axis below, gales cede to gusts and vicious whirlwinds, ice giants shout in the night. An inch of silt marks a thousand years, an aeon means a single degree of arc and by this scale a thaw is underway. There will be a century of centuries of snarling ice, an age of glacial strain until the first crystal's glistening melts to liquid spreads and seeps and creeps north across the frozen surface to make of it a mirror wherein the sun might see its face... The nights are cold enough to strip the lungs of any beasts foolish enough to venture on this wasted acreage, the wind which blasts across the vista turns hide and flesh to stone. There are shelves where the sun never reaches and salts forced by the pressure lie as powder on the surface. (Norfolk 1998, 3-4)

The impressive description could be dismissed as the author's bravado. It is, however, perhaps more appropriate to take Norfolk seriously and to think about the implicit meaning of the passage. First we can see the author stepping one time level down, before history, trying to speak to us, the readers, from the level of myth. While previously mythical structure was just repeated, now a different approach is applied, since the author imitates the steps of the myth-maker and describes natural processes through human metaphors. The text approaches myth in tone, yet it can never acquire the status of myth, simply because Norfolk cannot get rid of his position as a modern writer. As such he must be at all times conscious of his location in time, from which it is impossible to speak in the form of myth. All he can try is to write a pastiche, but his word, signed by a contemporary writer, can never aspire to the same status as the words of the Ancient author. 
A metaphor that comes as natural in myth feels inappropriate in a modern, albeit historical, novel and reveals another layer of meaning. This layer is concerned with criticism of contemporary society and here the author builds, to a certain extent, on Lempriere's Dictionary. While his first novel concerns itself mainly with merciless early capitalism, in The Pope's Rhinoceros it is the destructive relationship to nature. A. S. Byatt is right to point out that "the effect is double - to diminish the importance of human events, and at the same time to create a paradisal nostalgia (there are Miltonic echoes also) for the plenitude of a natural world unpolluted by humans" (69). This insight is supported by the geographic scale of the novel, the main plot of which is set in Rome, the metropolis of the Christian world, but reaches out to the very margins of the contemporary world: it starts in the North Sea and the "rhinoceros" of the title is being hunted in rainforests. Nature is reduced to a mere source of "entertainment". The decadent Pope desires a rhinoceros since it is an "enigma" for him and the rival parties, i.e., the Portuguese and Spaniards, compete for whom will supply the rhino to the Pope's court, thus winning the Pope's favour.

Norfolk manages to steer his novel to a rather vague and extravagant ending which could not be more different from the thriller-like ending of Lemprière's Dictionary, but at this point readers are so confused that they are hardly able to follow the plot. They have been locked in a labyrinth of words and scenes, and the above-quoted lyrical passages on the birth of the continent are contrasted with a detailed description of the sixteenth century streets of Rome in which the readers are not spared a single sensual impression. Obsessively, Norfolk pays attention to details that could easily be omitted from the story (the fauna and flora of rainforests, Church law, issues related to the transport of large animals, monastic orders, etc.) but they, eventually, play their role in the novel, as they only strengthen the contrast between the majesty of nature and the rat race of human history, and to such an extent that perhaps it is not appropriate to speak of a contrast. The levels are incommensurable.

This conclusion, however, casts doubts on this reading of the novel. If we accept the ecological interpretation (the story describes nature in the Renaissance and serves as a foreboding of what happens, in much larger measure, today, while it is not the principle but only the intensity of destruction that is different), then a comparison with the long geological time necessarily undermines such a reading. Strictly speaking, compared to the long geological time, the fury of human life - regardless whether in the sixteenth century or now - is quite insignificant. It looks as if the author hesitated whether to 
embrace social-ecological criticism or a fatalistic conception of human fate. No matter what reading we choose, the strong visual image, almost a large canvas, or the "landscape of history" remains the strongest impression of the novel, again pointing to the insignificance of individual human lives.

Even more obscure, however, is the message of Norfolk's next novel, In the Shape of a Boar. Here, too, we get down to a mythical level right at the outset:

They come from the cities of Pherae and Phylace on the plain of Thessaly, from Iolcus on the Magnesian coast, Larissa and Titaeron on the banks of the Peneus. They quit Naryx and Trachis and march inland, westward, by way of the tusked peaks of Mount Otea and the hot basins of Thermopylae. Rivers lead them out of Argolis, Emathia and Locris - the Asopus, the Axius, the Cephisus - and from Megara and Athens their routes lie across the isthmus of Corinth. They sail east from Ithaca and Dulichion; west from Aegina and Salamis. The heroes are the outposts of a shrinking country whose centre is the the place of their assembly. They march towards its discovery, each step drawing the ring of the tinchel tighter about the ground where their tracks must meet. They are one another's quarry in a bloodless, preparatory hunt. (Norfolk 2000, 3)

This is, naturally, nothing else than an echo of The Iliad, in particular its beginning, when Nestor refers to the past as something which provides foundations for the present, thus providing it with a claim on being and legitimacy. Stories narrated by Nestor had happened in the distant past but their truth is not contested. They are what can be built upon and what can serve as a basis for further stories. Same as in The Pope's Rhinoceros, here too the author realises that he will not be able to create a myth. Whereas in the former book he goes for fictitious account of geological processes, in the latter he opts for almost an academic way of writing. The first few dozen pages are accompanied by detailed, almost overblown footnotes the purpose of which is to anchor every described fact in some older record, already treated in literature. Thus the footnote to the very beginning of the book, quoted above, reads:

Hdt vii. 176.2-3; Paus i.4.2., iii.4.8, x.20.1; qua saepto, Paus i.1.3; qua patria advenarum Doriarum, Paus v.1.2; Apollod ii.7. 14; qua situ mortis Herculis, Lucian Hermotimus vii; De Morte Peregrini xxi; Soph, Trach 1191ff., Philoc 
801-3; Schol ad Hom, Il ii. 724; Diod Sic iv.38.3-8; Ov, Met ix.229ff.; Hyg, Fab xxxvi, cii; Sen, Her Oet 1483 ff.; Serv ad Virg, Aen viii.3oo; Anth Gr vi.3; qua situ sepulcri Deianeirae, Paus ii.23.5; re denten, Lyc, Alex 486, cf. Xen, Cyn x17. (Norfolk 2000, 3)

As if a reference in the work of the ancient authorities established a stronger claim on being. The first part of the novel might be seen as a prologue. Readers will no doubt be reminded of The Pope's Rhinoceros, waiting to be thrown into the plot of the novel, but it never arrives. The "prologue" is stretched to over a hundred pages, so after a while it is no longer perceived as a prologue but as a book in its own right - as if the writer tried to bring us back to the level of myth. His narration is colourful, vivid, enthralling, and as readers we easily succumb to its rhythm and immerse ourselves deeply into the story. Even the scaffolding of references disappears after three dozen pages and we find ourselves in the thick of a mythical hunt for the Kalydonyan boar. We are returned to "reality" only at the end of the passage when the footnotes resurface - this time as if to anchor the end of the chapter which will, however, be left open. Norfolk repeats the Ancient myth but stops just in front of the cave where the boar is hiding. The mythical passage ends as abruptly and surprisingly as it was unexpectedly prolonged.

The second part of the novel takes us into the twentieth century, where we follow a plot spread across two time levels, distant from one another about two dozen years. The first is set in Czernowitz, Bukovina, the other in Paris. At first sight, it is the first level which will immediately command our attention since there is something mythical about it. Compared to the "prologue", it is relatively close to our period, but nevertheless takes place in a world which seems light years away, same as the world of Greek myths - it is a world before the terrors of WWII, a world still innocent to a certain degree and, at the same time, much more varied. It is not a paradise, Norfolk hints, rather a world in the shadow of the imminent apocalypse which it is not in the power of local inhabitants to fend off: "His father was drinking with Peter Walter, who worked as a finisher in the Lupu furniture factory and lived in Flurgasse. They had a plan to emigrate with their families to South America which both knew would never be put into effect but which nevertheless required lengthy discussions two or three times a week" (Norfolk 2000, 130). Soon afterwards the world of the cultural variety falls prey to WWII atrocities, which will brutally impact the three protagonists: the main hero Solomon 
Memel, his former girl-friend Ruth, and Jakob Feuerstein. For long years they are separated by the war. Solomon flees the Nazis, finding refuge among the partisans in the mountains of Greece and later describing his experience in the poem called Die Keilerjagd, published after the war by a small Viennese press. The poem became an immediate success and quickly it found its way into the curriculum as a respected classic.

As Thomas Jones has remarked in The London Review of Books, the book is "a kaleidoscope of triangles: myth, history, literature; Sol, Jakob, Ruth; Atalanta, Meilanion, Meleager; Sol, Thyella, her lover Xanthos, whose name means 'yellow', which associates him with blond Meleager; the three parts of the novel; the three narrative strands in Part Two - but none of these maps neatly onto any of the others, and any hopes for a schematic solution will be frustrated" (26-27).

Here Norfolk may be making fun of a fashion among novelists to set their novels on multiple time levels where one reflects another or offers a clue to interpret it. Possession (1990) by A. S. Byatt and Hawksmoor (1985) by Peter Ackroyd are among the best examples of this trend. The former is a campus novel about an adventure in scholarly research, combined with a love story. Hawksmoor is a well-paced crime novel inspired by the peculiar architecture of London churches. Both books share an esoteric relationship to history which can be summarised in this way: what has once happened will happen again, so it is in history where we should be looking for a key to unravel the present. This is not historicism, rather parallelism. Two levels in different periods mirror one another and in between there is a void.

The basic structure of Norfolk's novel resembles this only on the surface. The illusion dissolves as soon as the reader realises that the relationships between the time layers are vague or obscure and that any attempt to articulate them means to start reading a completely different book. The first mythical episode is a world closed in itself and it is only at the end of the novel that we realise why the author accentuated a character who is rather neglected in the traditional myth. The second and third parts, i.e., the one taking place before the war and the one taking place in the sixties, are connected by a seemingly strong link - by their protagonists. These are figures whose story started at a certain point and certain time, then their lives were distorted by events we do not see and now the story continues. But is it really like this?

The answer to this question is far from clear. To a certain extent the relation between two "realistic" levels is as vague as the relation between them and 
the mythical level. The gap is filled by memories, stories, narrations made ex post, so there is always something mythical about the past, be it in motifs or - and above all - in the very layout of the narration.

This interpretation is supported by the problem surrounding the poem written by the main hero. As has been said above, Die Keilerjagd builds upon the author's experience, while touching upon some deeper level as well. From the little we may grasp of the poem we can infer that it is close to myth in its nature: it transforms individual experience into something which has a more general effect, but in doing that reaches the limits of articulation. Perhaps this is the reason why Solomon cannot - or rather does not want to - defend himself when he is accused of having written an inauthentic poem, in which some details do not correspond to reality (dolphins in the Gulf of Corinth). The question whether the story of the poem is true, however, remains unresolved. And looking back, we find that the vague ending is something that all three parts of the novel share.

Despite this it seems as if the author challenges the reader to make his/her own interpretation. But this challenge has a peculiar form as it is took external form, through the author's publisher. Before the press conference at which the book was launched it was announced that the story of the book had been inspired by the life of the Jewish poet Paul Celan. There are, no doubt, some shared aspects: the motif of the boar, which appears in Von Schwelle zu Schwelle by Celan, childhood spend in Czernowitz, suffering during the Nazi and the Soviet? occupation, as well as the threat to his moral and literary reputation during his stay in Paris, which was to end tragically for Celan. There are differences though: Paul Celan did not end among partisans in the hills, but in a labour camp; the controversy surrounding his work was not about wrong facts but - equally nonsensically - the charge of plagiarism. Norfolk's novel cannot, therefore, be read as a biography of Paul Celan. Perhaps it could be read as an alternative one but then it makes no sense to speak of biography. There is something much more interesting. The life of Paul Celan - like the fate of European Jewry during holocaust - was indeed terrible and might serve as a matter for a story: a young man growing up in a city where different cultures meet, disintegration of the established world, atrocities, first poetic achievements, move to Paris and a poisonous attack from a widow by a man whom he had himself helped. Norfolk, however, seems not to be interested in all of this and instead writes a completely different story. Yet at the same time he is willing to draw attention to similarities to Celan's life. The question is why. 
Evidently he is concerned with the gap opening between life and narrative. A gap in which particularities disappear and from which story as myth emerges. This gap - or a dark cave, to use the metaphor of Norfolk's "prologue" - is a source of literature as well as its eternal enigma. Literature does not represent but narrates and creates out of inspiration which forever remains beyond words. In this remarkable novel, the poetry of Paul Celan, remote, gloomy, obscure and mysterious, close to myth, is evoked - and it is this ground that Norfolk wants to tread with his novel. The novel cannot be the biography of the poet, and it is in fact irrelevant whether Sol is Paul Celan or not. They share some things, differ in others. For Norfolk, identity is just an accident, something irrelevant which gets lost in the story or myth.

He returns to the topic of myth in his next novel, published twelve years later (some of this time was taken by work on an ambitious, later abandoned novel The Levels, which was to be set in Britain in three different periods: at the end of the Roman time, during WWII and in 1981). Fohn Saturnall's Feast reaches to pre-Christian England, the myths of which the author is about to use in a historical fresco from the seventeenth century Civil War.

As far as the structure of the text is concerned, the author opts for a similar approach as he did in previous novels. Unfortunately, the resulting text is hardly comparable. Lavish descriptions of historical landscape with all the details seem to promise more than it actually delivers. While in The Pope's Rhinoceros we get from a vision of Europe being born to a story which is truly global, a panoramic view of Renaissance Europe, and In the Shape of a Boar we get from a pastiche of a Homeric myth to a meditation on the nature of literature, fohn Saturnall's Feast, albeit superbly written, offers a story that just cannot fulfil the ambition outlined at its beginning. John Saturnall, a son of a local herbalist, resembles John Lemprière in many respects. He, too, enters the world with a handicap (he is of unprivileged origin and background, subject to distrust and bullying) which is, however, offset by some special skills. Whereas John Lemprière excels in Roman mythology, John Saturnall is endowed with an almost supernatural sense of smell, so that he can tell individual ingredients in even the most delicate dishes, which predetermines him for a career as a cook. As such he is to fulfil the legacy of his mother and organise what is called "The Feast": a carnival-like ritual, the tradition of which dates back to the pre-Christian era, when it was a version of the Roman saturnalia - John's surname is more than telling.

We follow John's story from his early youth when he is bullied by other children in the village, accompany him during a difficult stage in his life when 
he loses his mother and with some good luck gets a position as a cook in a Somerset mansion. He grows, personally and professionally, falls in love with the wrong person, goes through the Civil War and experiences a fairy-tale ending to his story.

Compared to the author's debut novel, however, the story is much less prominent. Rather, it serves as a kind of vehicle for excellent and detailed descriptions. Norfolk's fans will emphasise mainly this aspect of the book and it is evident why. The novel presents the reader with a hyper-realistic perspective on seventeenth-century English cuisine, and it is a spectacular view indeed. The pre-revolutionary cuisine is rich and varied and Norfolk takes pleasure in minute details. However, here we must pause and ask ourselves the question to what extent fohn Saturnall's Feast is a novel and to what extent it is a study in cultural history. The scope and detail can be compared to works of contemporary historians of every day life, such as Jean Delumeau or Richard van Dülmen. A comparison with historiography is further emphasised by the fact that Norfolk's descriptions of cuisine is not just an ornament but is actually significant.

During the seventeenth century - if we are to believe Norfolk - English cuisine underwent several transformations reflecting changes in society and historical events. As an apprentice, John Saturnall enters a world which is almost autonomous, its highest purpose being not to appease hunger but to create decadently refined dishes which will satisfy the aestheticism of the ruling class. Such an attitude to food, necessarily, found little support with the Puritans. Combined with the historical conditions, all of this transforms John Saturnall from a cook in an aristocratic household into one who makes food for Puritan soldiers. Naturally, after the Restoration habits are changed again, gourmet cuisine restored or even elevated to yet a higher position. Judged from this perspective, fohn Saturnall's Feast could be read as an immensely interesting cultural history, served in the attractive form of a novel.

However, the cuisine aspect does not exhaust the potential of the novel. What is equally interesting is what is said in between the lines or what remains unsaid. It is behind the page where we suspect the presence of the greatest poet of that time, John Milton, and the atmosphere in society is exactly that as described by Thomas Hobbes. Homo homini lupus echoes especially strongly in passages on the Civil War. Here, Norfolk's account is quite commonplace. We know that the seventeenth century in England was gloomy, stormy and violent as well as extremely fruitful in developments in science and culture. 
It is Milton who is more interesting for Norfolk though. The poet who wanted to "justify the ways of God to man" is rightly seen as the greatest English poet of the seventeenth century. Paradise Lost, the story of the Fall, gives the reader only a glimpse of Eden which is understood by Milton within Christian theology (the Garden is lost because of sin and a return is possible only through eschatology). Against this Norfolk posits a quite different version of the Garden. It is a pagan, mythical vision but its present realisation is more accessible - the memory of the Garden is still alive and can be awakened by a feast, carnival, saturnalia.

Maybe this is the key to the whole novel. True, fohn Saturnall's Feast can be read as a provocative alternative to the historical picture of English literature and culture in the seventeenth century. Norfolk's story provides an interesting counter-point to the dominant Puritan discourse, represented by authors such as Milton or Bunyan. Viewed from that angle, it is an interesting book, learned, crossing the boundaries of fiction and entering cultural history. From a critical perspective, however, it is a question whether this is sufficient to make a good novel.

Lawrence Norfolk seems to test the boundary he has tried to transcend throughout his career. The same approach is applied here, yet, for all its descriptive bravura, it just does not seem to work here: the story borders on fairy-tale banality, unable to support such an ambitious novel. However interesting Norfolk's research and cultural history is, it is not sufficient to make a novel. Not because of lack of skills on the part of the author, but simply because his transgressive approach to the genre has exhausted itself.

Even if Norfolk's last novel can be - from a critical perspective - considered not his greatest achievement, it still remains inspiring and is in line with the author's literary output. It revels in painting what I called "the landscape of history", large vistas on history which emphasise two ideas: a certain privileged position that we occupy since it is we who gaze at history; and, second, the insignificance of individual beings vis-a-vis history or historical time. In this, Norfolk's novels are anti-humanist. They draw attention to changes and movements that remain outside the boundaries of human power and show human beings swept by currents and forces the origin of which they are often unable to understand. These novels are indeed "landscapes" - they invite us to gaze and to attempt to articulate what we see; yet any translation into clearly defined concepts will remain elusive. 


\section{Works Cited}

Boccardi, Mariadele. The Contemporary British Historical Novel, Representation, Nation. London: Palgrave Macmillan 2009. Print.

Bradbury, Malcom. The Modern British Novel. London: Penguin 1993. Print. Elias, Amy J, Sublime Desire, History and post-1g6os Fiction. Baltimore: The John Hopkins University Press 2001. Print.

Jones, Thomas. "Dark Sayings." London Review of Books. Vol. 22, No. 21, November 2, 2000. Print.

Keen, Suzanne. Romances of the Archive in Contemporary British Fiction. Toronto: Toronto University Press 2001. Print.

Norfolk, Lawrence. Fohn Saturnall's Feast. London: Bloomsbury 2013. Print. ---. Lemprière's Dictionary. New York: Harmony Books 1991. Print.

---. The Pope's Rhinoceros. London: Vintage 1998. Print.

---. In the Shape of a Boar. London: Weidenfeld \& Nicolson 200o. Print.

Ziolkowski, Theodore. Lure of the Arcane, The Literature of Cult and Conspiracy. Baltimore: The John Hopkins University Press 2013. Print.

LADISLAV NAGY is the head of the Department of English at the Faculty of Arts, University of South Bohemia in České Budějovice. He received his PhD from the Department of Anglophone Literatures and Cultures at the Faculty of Arts, Charles University, and specialises in contemporary fiction and English literature. He is the author of London Same \& Different published (in Czech) by Arbor Vitae. In memoriam, a book of essays on contemporary historical fiction, is currently being edited for publication and will be published shortly.

lnagy@ff.jcu.cz 